NASA/TM-2002-211794

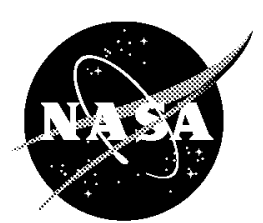

\title{
Turbine Engine Clearance Control Systems: Current Practices and Future Directions
}

Scott B. Lattime

Ohio Aerospace Institute, Brook Park, Ohio

Bruce M. Steinetz

Glenn Research Center, Cleveland, Ohio 
The NASA STI Program Office ... in Profile

Since its founding, NASA has been dedicated to the advancement of aeronautics and space science. The NASA Scientific and Technical Information (STI) Program Office plays a key part in helping NASA maintain this important role.

The NASA STI Program Office is operated by Langley Research Center, the Lead Center for NASA's scientific and technical information. The NASA STI Program Office provides access to the NASA STI Database, the largest collection of aeronautical and space science STI in the world. The Program Office is also NASA's institutional mechanism for disseminating the results of its research and development activities. These results are published by NASA in the NASA STI Report Series, which includes the following report types:

- TECHNICAL PUBLICATION. Reports of completed research or a major significant phase of research that present the results of NASA programs and include extensive data or theoretical analysis. Includes compilations of significant scientific and technical data and information deemed to be of continuing reference value. NASA's counterpart of peerreviewed formal professional papers but has less stringent limitations on manuscript length and extent of graphic presentations.

- TECHNICAL MEMORANDUM. Scientific and technical findings that are preliminary or of specialized interest, e.g., quick release reports, working papers, and bibliographies that contain minimal annotation. Does not contain extensive analysis.

- CONTRACTOR REPORT. Scientific and technical findings by NASA-sponsored contractors and grantees.
- CONFERENCE PUBLICATION. Collected papers from scientific and technical conferences, symposia, seminars, or other meetings sponsored or cosponsored by NASA.

- SPECIAL PUBLICATION. Scientific, technical, or historical information from NASA programs, projects, and missions, often concerned with subjects having substantial public interest.

- TECHNICAL TRANSLATION. Englishlanguage translations of foreign scientific and technical material pertinent to NASA's mission.

Specialized services that complement the STI Program Office's diverse offerings include creating custom thesauri, building customized databases, organizing and publishing research results ... even providing videos.

For more information about the NASA STI Program Office, see the following:

- Access the NASA STI Program Home Page at http://www.sti.nasa.gov

- E-mail your question via the Internet to help@sti.nasa.gov

- Fax your question to the NASA Access Help Desk at 301-621-0134

- Telephone the NASA Access Help Desk at 301-621-0390

- Write to: NASA Access Help Desk NASA Center for AeroSpace Information 7121 Standard Drive Hanover, MD 21076 
NASA/TM-2002-211794

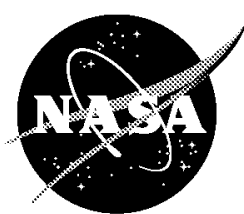

\section{Turbine Engine Clearance Control Systems: Current Practices and Future Directions}

Scott B. Lattime

Ohio Aerospace Institute, Brook Park, Ohio

Bruce M. Steinetz

Glenn Research Center, Cleveland, Ohio

Prepared for the

38th Joint Propulsion Conference and Exhibit cosponsored by AIAA, ASME, SAE, and ASEE

Indianapolis, Indiana, July 7-10, 2002

National Aeronautics and

Space Administration

Glenn Research Center 


\section{Acknowledgments}

The authors acknowledge Mr. Kevin J. Melcher, Instrumentation and Controls Division, NASA Glenn Research Center, for his thoughtful comments and suggestions on the manuscript. The authors also acknowledge the NASA

Glenn Revolutionary Aeropropulsion Concepts (RAC) Project for supporting this research.

Trade names or manufacturers' names are used in this report for identification only. This usage does not constitute an official endorsement, either expressed or implied, by the National Aeronautics and Space Administration.

The Aerospace Propulsion and Power Program at NASA Glenn Research Center sponsored this work.

Available from

NASA Center for Aerospace Information 7121 Standard Drive

Hanover, MD 21076
National Technical Information Service 5285 Port Royal Road Springfield, VA 22100

Available electronically at http://gltrs.grcnasa.gov 


\title{
TURBINE ENGINE CLEARANCE CONTROL SYSTEMS: CURRENT PRACTICES AND FUTURE DIRECTIONS
}

\author{
Scott B. Lattime* \\ Ohio Aerospace Institute \\ Brook Park, Ohio 44142 \\ Bruce M. Steinetz ${ }^{\dagger}$ \\ National Aeronautics and Space Administration \\ Glenn Research Center \\ Cleveland, Ohio 44135
}

\begin{abstract}
Improved blade tip sealing in the high pressure compressor (HPC) and high pressure turbine (HPT) can provide dramatic reductions in specific fuel consumption (SFC), time-on-wing, compressor stall margin and engine efficiency as well as increased payload and mission range capabilities. Maintenance costs to overhaul large commercial gas turbine engines can easily exceed $\$ 1 \mathrm{M}$. Engine removal from service is primarily due to spent exhaust gas temperature (EGT) margin caused mainly by the deterioration of HPT components. Increased blade tip clearance is a major factor in hot section component degradation. As engine designs continue to push the performance envelope with fewer parts and the market drives manufacturers to increase service life, the need for advanced sealing continues to grow. A review of aero gas turbine engine HPT performance degradation and the mechanisms that promote these losses are discussed. Benefits to the HPT due to improved clearance management are identified. Past and present sealing technologies are presented along with specifications for next generation engine clearance control systems.
\end{abstract}

\section{BACKGROUND}

Gas path sealing has been and continues to be a fundamental concern in aircraft gas turbine engines. Since the late 1960 's, blade tip and interstage sealing has taken on a prominent role in aircraft engine design.

*Senior Research Associate, Member AIAA

†Senior Research Engineer, Associate Fellow AIAA
Blade tip sealing has been a challenging problem since the development of the gas turbine engine. It is such because the clearance between the blade tips and surrounding casing (shroud) tends to vary due primarily to changes in thermal and mechanical loads on the rotating and stationary structures. This is true for both land based and aero engines, however tip sealing is more challenging for the latter due to the frequency of changes in operating points as well as inertial (maneuver) and aerodynamic (pressure) loads during flight. These loads and others will be further explained in the following sections.

Improved sealing in both the high pressure compressor (HPC) and high pressure turbine (HPT) can provide dramatic reductions in specific fuel consumption (SFC), compressor stall margin and engine efficiency as well as increased payload and mission range capabilities. Improved clearance management, especially in the HPT, can dramatically improve engine service life or time-on-wing (TOW). Deterioration of exhaust gas temperature (EGT) margin is the primary reason for aircraft engine removal from service. ${ }^{1}$ The Federal Aviation Administration (FAA) certifies every aircraft engine with a certain EGT limit. EGT is used to indicate how well the HPT is running, specifically, it is used to estimate HPT disk temperature. As components degrade and clearances increase (especially in the HPT), the engine has to work harder (hotter) to develop the same thrust. Once an engine reaches its EGT limit, an indication that the HPT disk is reaching its upper temperature limit, the engine must come off the wing for maintenance. Maintenance costs for major overhauls of today's large commercial gas turbine engines can easily exceed \$1M. 
Wear mechanisms of blade tip seals can be generally categorized into three major categories, namely, rubbing (blade incursion), erosion, and thermal fatigue. With the advances in material processing and coatings, the third category is of little concern in comparison to the rubs and erosion, provided proper cooling of the shroud and blade tips is maintained. Cooling can be compromised by wear, erosion, and fouling of the blades due to blockage and distortion of cooling passages. Although erosion is a major component of tip seal wear, the causes behind erosion are beyond the scope of the present work and the authors have focused their attention on tip seal degradation due to blade rubs. Blade rubs are expected to occur throughout the service life of an engine. Engine build clearances are in fact chosen to achieve some amount of blade incursion at extreme operating conditions (e.g., takeoff, re-accel) such that the tip seals will be honed to operate line-toline when those conditions are repeated after the engine has been "run-in." Rubs can also contribute to accelerating the effects of both erosion and thermal fatigue by wearing protective coatings (e.g., thermal barrier coatings) or distorting cooling passages of the blade tips during an incursion event.

The interest of this work is concentrated on blade tip clearance management in the HPT. This is the location that reaps the most benefits (e.g., efficiency, service life) from clearance management, although the HPC can also attain large gains (e.g., stability, stall margin). Kawecki reported on a study to assess the benefits of improved tip sealing for both military fighter (low bypass ratio) and transport (high bypass ratio) applications. ${ }^{2}$ He determined benefits in life cycle costs (LCC) for a large number of clearance control schemes considering acquisition cost, maintenance, reliability, weight, and fuel savings. Kawecki showed that improved tip clearances in the HPT resulted in LCC reductions four times that for the LPT and twice that of the HPC. He also determined that the benefits for the transport aircraft were twice that of the fighter aircraft.

There have been a number of government, military, and commercially sponsored research programs to define and quantify gas turbine engine deterioration and to quantify the performance losses associated with such deterioration. Olsson and Martin reported on flight loads and their effects on performance deterioration of a Pratt \& Whitney JT9D jet engine due to increased blade to outer-air-seal running clearances. ${ }^{3}$ Engine flight loads and their effects on clearance and performance were measured in both the fan and HPT sections.
Researchers found that of the three types of flight loads, aerodynamic, inertial and gyroscopic, only aerodynamic and inertial loads played a major role in engine performance. These loads contributed mostly to fan clearance closures that occurred at takeoff rotation during maximum angle of attack. However, the combination of aerodynamic loads, thrust bending and thermal expansion during climb contributed to the minimum clearance in the HPT. The authors also noted that high " $G$ " turns and maneuvers in combination with high power operation and aerodynamic loads also contributed to HPT clearance closure. Howard and Fashing reported on performance degradation due to increased airfoil tip radial clearance and stator out-ofroundness effects in a General Electric CF6-50 jet engine during an engine test stand study. ${ }^{4}$ Investigators measured HPT tip clearance and stator out-ofroundness during both steady state and transient operation. Clearance changes due to throttle transients such as takeoff, decel, reburst, and restart were obtained during ground testing.

\section{MECHANISMS OF HPT TIP CLEARANCE VARIATION}

Figure 1 shows the HPT blade tip seal location in a modern gas turbine engine. ${ }^{5}$ The figure shows a cross section of the combustor and two-stage HPT. The turbine disk, blade, and tip seal of the first-stage turbine are labeled. Blade tip or outer air seals line the inside of the stationary case forming a shroud around the rotating blades, limiting the gas that spills over the tips. Blade tip clearance, as mentioned previously, varies over the operating points of the engine. The mechanisms behind these clearance variations come from the displacement or distortion of both static and rotating components of the engine due to a number of loads on these components. The loads can be separated into two categories, namely engine (power-induced) loads and flight loads. Engine loads include centrifugal, thermal, internal engine pressure, and thrust loads. Flight loads include inertial (gravitational), aerodynamic (external pressure), and gyroscopic loads. Engine loads can produce both axisymmetric and asymmetric clearance changes (see Figures 2 and 3). Flight loads produce asymmetric clearance changes.

\section{AXISYMMETRIC CLEARANCE CHANGES}

Axisymmetric clearance changes are due to uniform loading (centrifugal, thermal, internal pressure) on the stationary or rotating structures that create uniform radial displacement as shown in Figure 2. Centrifugal and thermal loads are responsible for the largest radial variations in tip clearance. Centrifugal loads produce 


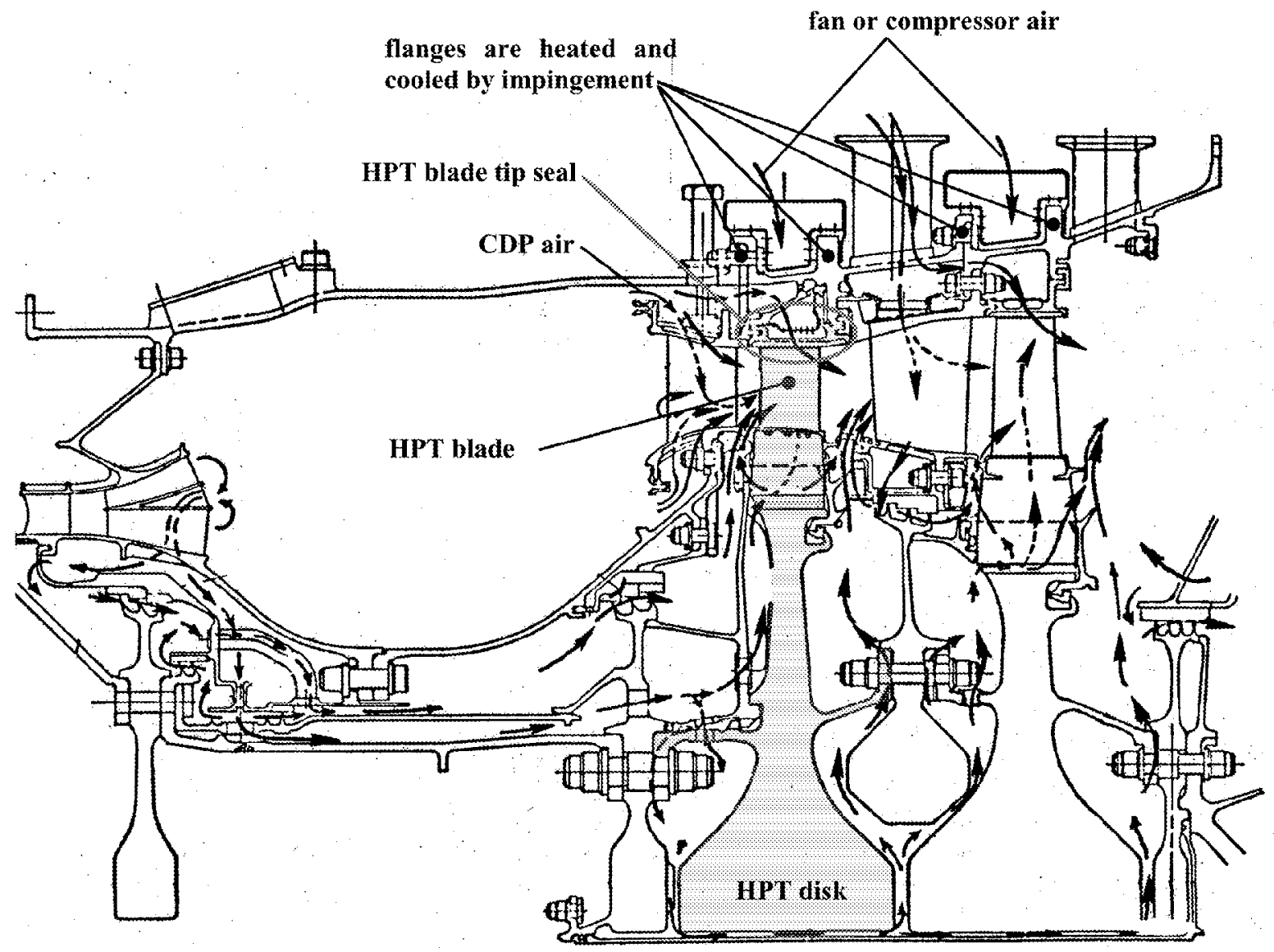

Figure 1: HPT blade tip seal location in a modern gas turbine engine ${ }^{5}$

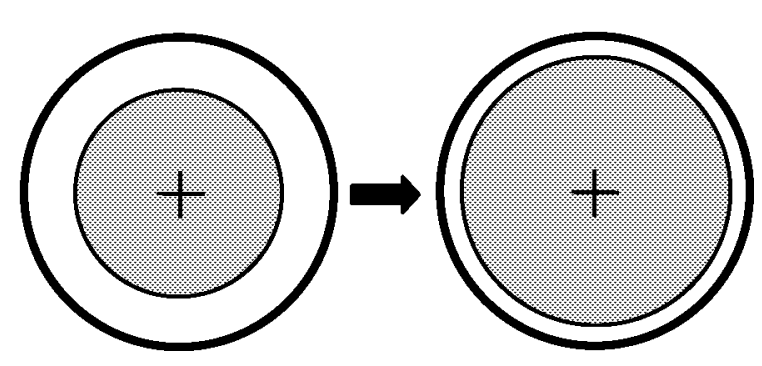

Figure 2: Axisymmetric clearance change

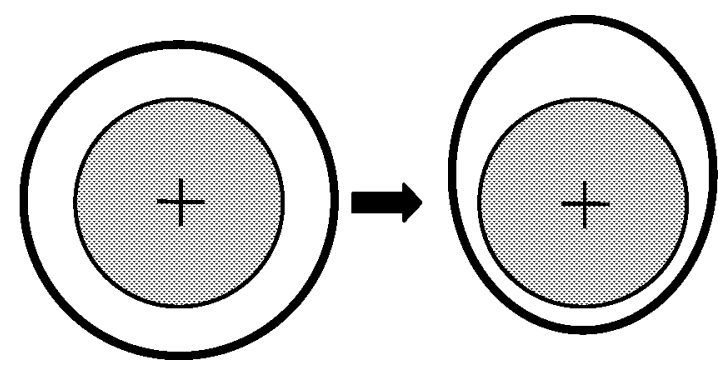

Figure 3: Asymmetric clearance change 
axisymmetric clearance changes by causing the rotor to expand or contract during changes in engine acceleration. Thermal loads produce both axisymmetric and asymmetric clearance changes due to the thermal expansion/contraction of the stationary and rotating structures and how uniformly these parts are heated or cooled. Because of large diameter bladed disks (over 36 in) and shrouds, the extreme variations in rotational speeds (over $10 \mathrm{krpm}$ ) and temperatures (over $2500^{\circ} \mathrm{F}$ ) create large displacements of these structures.

Figure 4 shows HPT tip clearance and speed as a function of time for a given mission profile due to axisymmetric loads. The major operating points throughout the mission profile have been labeled, namely takeoff, cruise, decel, and re-accel. The chart illustrates the response of the rotor and case due to changes in engine speed and temperature as well as the need for cold build clearances in an engine. Axisymmetric clearance changes over 0.030 -in are not uncommon during takeoff and re-accel events in large commercial engines (these clearance changes are even greater when flight induced asymmetric loads are included, as will be discussed in the next section). Clearance changes in military engines can be even greater due to the need for increased performance with less concern for efficiency. As a cold engine is started, a certain amount of clearance exists between the shroud and blade tips. This clearance is rapidly diminished as the engine speed is increased for takeoff due to the centrifugal load on the rotor as well as the rapid heating of the turbine blades, causing the rotating components to grow radially outward. Meanwhile, the case expands due to heating but at a much slower rate. This phenomenon can produce a minimum gap or "pinch point". As the case expands due to heating after the pinch point, the clearance increases. Shortly after the case expansion, the rotor begins to heat up (at a much slower rate than the case due to its mass) and the clearance closes again. As the engine approaches the cruise condition, the case and rotor reach thermal equilibrium and the tip clearance remains relatively constant. However, throttle transients that occur, such as a step change in altitude (i.e., collision avoidance), during cruise will change the tip clearance and must be accounted for when setting the design cruise clearance to avoid running the blades into the case. When the engine is decelerated (e.g., landing approach), the clearance is rapidly increased due to the mechanical unloading of the rotor and blades and the thermal lag of the case as it cools. If the engine is spooled up for the aircraft to climb or make an evasive maneuver, after being in a decelerated condition, such as an aborted landing, a second pinch point can occur. This scenario is termed a re-accel or re-burst event. In this case, the centrifugal growth of the rotating components is compounded by the thermal states of the rotor and stator. The larger thermal mass of the rotor cools much slower than the case, which contracts more rapidly around the blade tips. This situation can lead to even less clearance than during takeoff and may thus set the cold build clearance. The re-accel effect can also occur when reverse thrust is applied to slow the aircraft after landing. The power used with reverse thrust approaches that used for takeoff with again less remaining clearance due to the elevated rotor temperature.

Figure 4 shows two key concepts behind active clearance control (ACC). It is desired to lower the operating clearance during cruise. This is where the greatest reduction in SFC can be gained (longest part of the flight profile). On the other hand, it is desired to open the clearance during the pinch point conditions to avoid rubs (minimal clearance must be maintained at takeoff to ensure thrust generation as well as keeping EGT below its limit). Hence, the goal of ACC is to maintain minimal clearance while avoiding rubs over the entire flight profile.

Possibly the worst-case re-accel scenario occurs during an in-flight shutdown (stopcock) followed by a restart or relight. This event is required during aircraft acceptance testing, where the engine is shut down at altitude followed by a dwell time during which the engine continues to rotate (windmill) due to the aircraft's forward momentum and is finally restarted and accelerated back to the power setting from which the engine had been shut down. Because the engine is shut down, not just decelerated, the case cools even more than a normal re-accel scenario, albeit the centrifugal effects on the rotor are much less due to the decreased speed (windmill speeds are less than ground idle). Restarting and then accelerating the engine may create more clearance closure than a takeoff condition due to the reduced temperatures of both the case and rotor. This is of course dependent on the dwell time before restarting the engine. Figure 5 shows engine test stand HPT clearance data for a GE CF6-50 during a stopcock event. ${ }^{4}$ Clearance change and core speed are shown as a function of time as core speed is cut from cruise power, restarted after a three-minute dwell time and brought back to a ground idle power setting. The chart shows a 0.037 -in increase in clearance due to the 9-krpm reduction in core speed and HPT blade cooling effects. During the three-minute dwell period, the case begins to cool and contract around the blade tips, closing the clearance about 0.020 -in. As the engine is restarted and brought to ground idle, the 6-krpm 


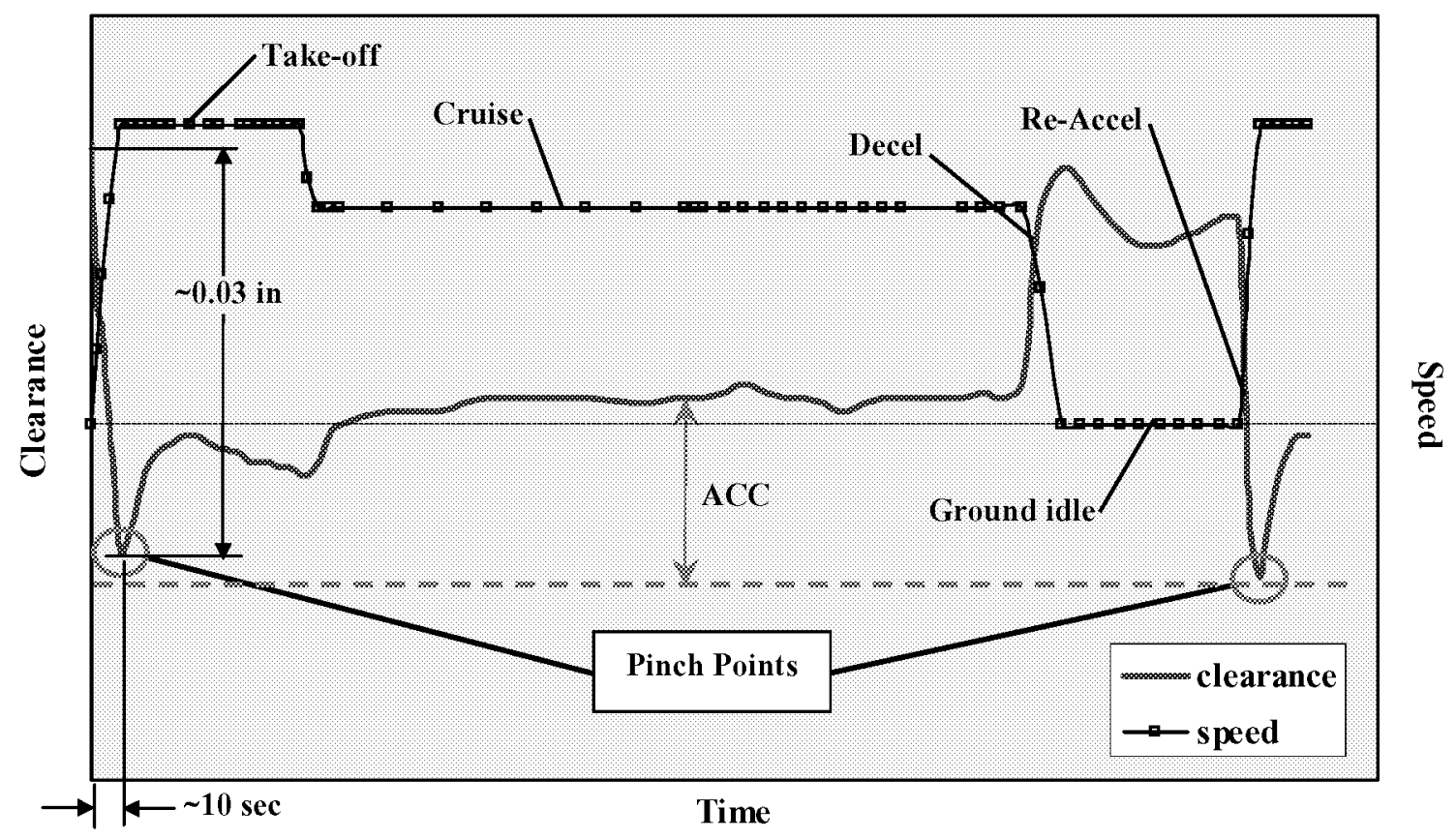

Figure 4: HPT tip clearance as a function of time over a given mission profile

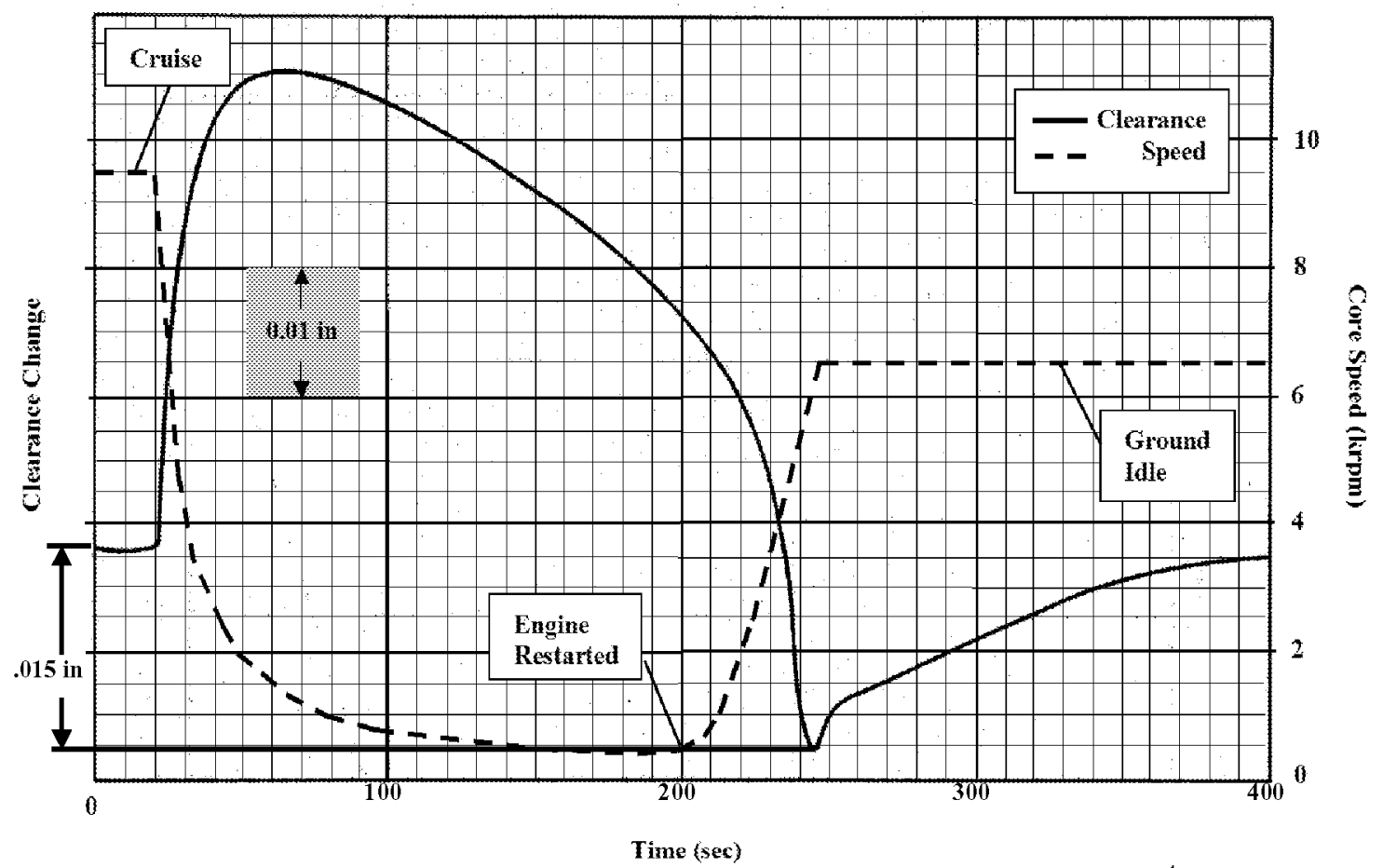

Figure 5: CF6-50 HPT tip clearance as a function of time during stopcock event ${ }^{4}$ 
increase in core speed and heating of the HPT blades produces a closure of approximately 0.034 -in and reduces the clearance about 0.015 -in from what it was at the cruise condition. Obviously, if the cruise clearance were set below 0.015 -in, a rub would have occurred.

\section{ASYMMETRIC CLEARANCE CHANGES}

Asymmetric clearance changes are due to non-uniform loading (thermal, thrust, inertial, and aerodynamic) usually on the stationary structures that create nonuniform radial displacement as shown in Figure 3. Distortion of the case due to non-uniform heating can cause the case or shroud to open clearances along a section or sections of the circumference while reducing them at others (e.g., ovalization). Asymmetric distortion of the case also comes from aerodynamic, thrust and maneuver loads (Figure 6). Because engines are not mounted to the aircraft on their centerlines (Figure 6a), aerodynamic and thrust load reactions create an applied moment on the case that causes the structure to bend relative to the rotor. Aerodynamic loads on the inlet cowl create shear forces and bending moments on the fan case that can carry through the engine, deflecting the cases throughout. These loads are created by the bending of the air stream entering the fan inlet and are thus dependent on fan airflow, inlet angle of attack, and aircraft speed (see Figure 6b). Aerodynamic loads are greatest just after takeoff rotation when the inlet angle of attack is most extreme. Aerodynamic loads during takeoff will generally act to distort the case such that closure occurs near the bottom center of the engine (i.e., the six o'clock position). Thrust loads also contribute to case distortion in a phenomenon commonly known as backbone bending. During takeoff, thrust loads create a downward pitch moment causing clearances to open towards the top of the engine while closing at the bottom, as shown in Figure $6 \mathrm{c}$. The opposite is true during reverse thrust, where now the pitching moment is up, closing clearances at the top and opening at the bottom. Olsson and Martin reported that typical backbone bending for the JT9D engine causes the front flange of the fan case to deflect upward more than the front section of the low speed rotor while the back end of the high speed rotor deflects downward more than the rear section of the core cases. ${ }^{3}$

Figure 7 shows the HPT clearance flight data presented by O1sson and Martin for the JT9D engine during takeoff. $^{3}$ Both HPT tip clearance change relative to ground idle conditions and core rotor speed are shown as a function of time during takeoff and low climb. The four clearance probe locations are shown schematically as viewed looking forward through the HPT. The chart clearly indicates minimum clearance to be located at about the five o'clock position of the HPT. The figure shows both the axisymmetric and asymmetric clearance changes due to engine and flight loads. Initially closure is due to the centrifugal effect with engine acceleration. As the engine continues acceleration to takeoff power, clearances begin to open axisymmetrically due to heating of the case but soon close along the bottom half of the HPT and increase along the top half due to the increasing thrust load on the engine. The asymmetric effect on clearance closure is further increased by the aerodynamic pressure loads on the inlet cowl, which transmit back to the HPT during climb. Figure 7 shows that the aerodynamic effects are most intense (steepest slope) just after takeoff rotation when the angle of attack is greatest and begin to decrease after low climb as this angle decreases. The maximum closure relative to ground idle appears to be about 0.055 -in occurring after low climb at about the five o'clock position of the HPT.

Table 1 shows the axisymmetric and asymmetric HPT closure data for the JT9D engine at the six o'clock position that was tabulated by Olsson and Martin. ${ }^{3}$ The table highlights the combination of engine (speed, thermal, thrust) and flight (aerodynamic and inertial) loads on the higher closure events such as climb, inflight restart, and thrust reverse as well as maneuver loads of hard turns and airplane stall. The most significant clearance changes are due axisymmetric effects of speed and blade heating. The highest total closure events occurred during climb after takeoff and a 2-G turn maneuver. Table 1 also indicates that thrust and flight load induced closures are of comparable magnitudes.

Transient dynamic loads can also occur during both aerodynamic and inertial loading conditions due to gusts and events like hard landings. Gusts affect both aerodynamic and inertia loads. Aerodynamic loads are derived from the change of inlet angle of attack associated with the gust component of the relative wind. Gusts or turbulence produce dynamic inertial loads due to the motion response of the structure to the gust. Figure 8 shows HPT clearance change during a hard landing and thrust reverse of a JT9D as reported by Olsson and Martin. ${ }^{3}$ The landing, which had a sink rate of $5 \mathrm{ft} / \mathrm{s}$ and a gross weight of $690,000 \mathrm{lbf}$ (much higher than revenue service), had virtually no effect on HPT clearance change. Closure is evident during the reverse thrust event. Backbone bending is shown to have the opposite effect as that during takeoff in Figure 8 as the clearance closures in the top half $(0.040-\mathrm{in})$ of the HPT are greater than those in the bottom half $(0.020$-in). Olsson and Martin reported that no gust 


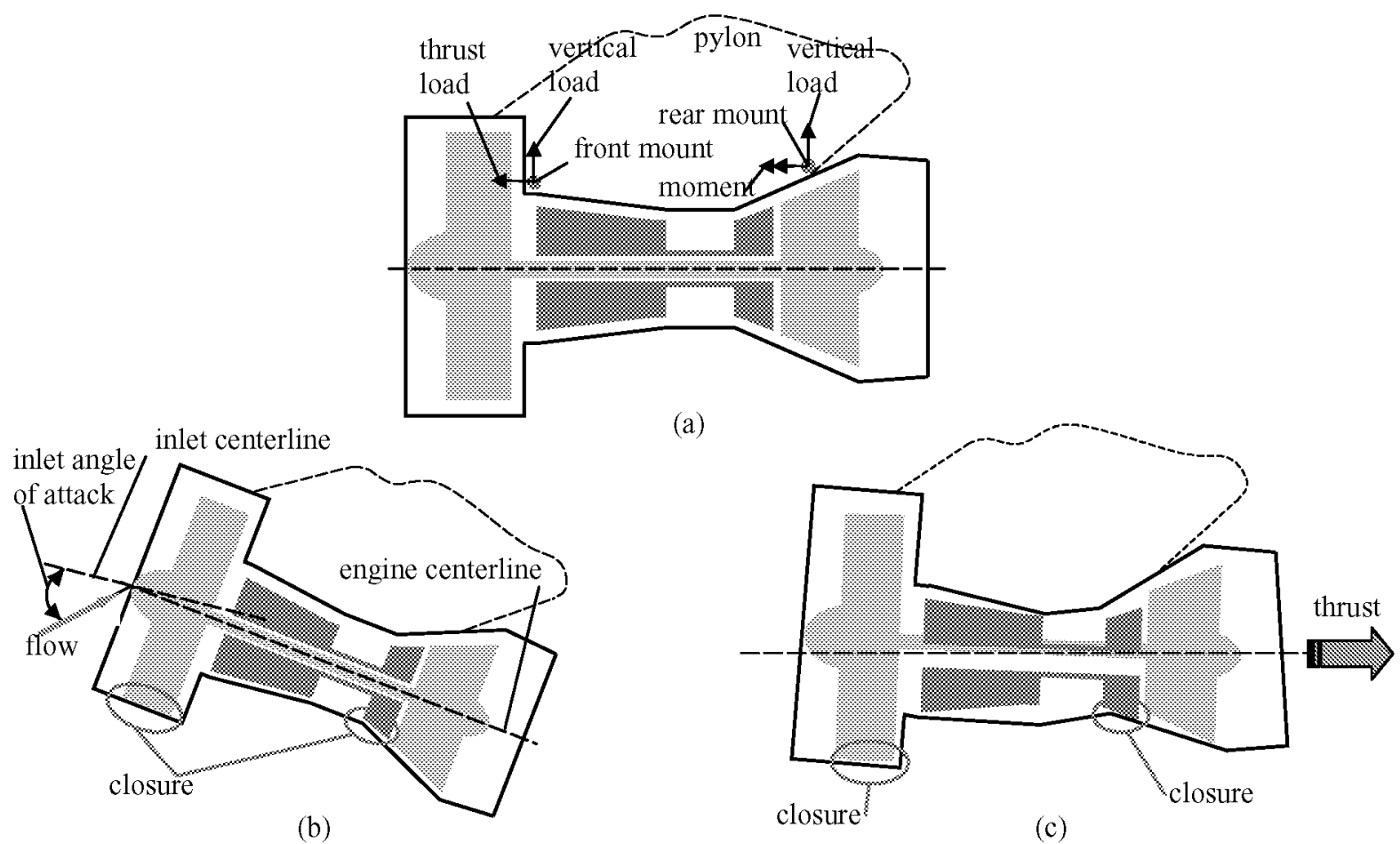

Figure 6: (A) Engine mounts and load paths, (B) Closures due to aero loads, (C) Closures due to thrust loads

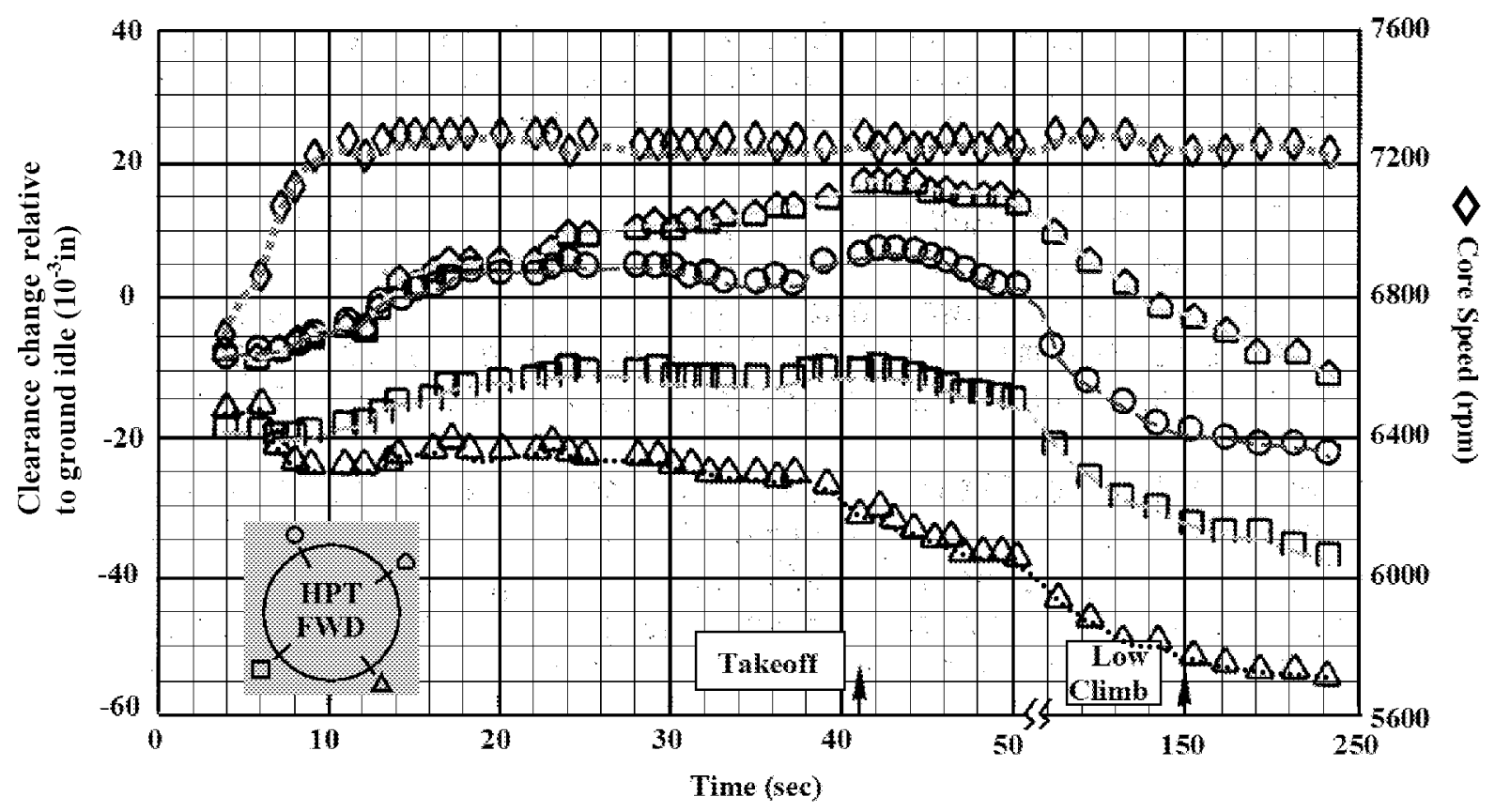

Figure 7: Engine and flight load effects during takeoff on HPT clearance of JT9D engine ${ }^{3}$ Note: $\Pi$ are estimates of $\square$ measured data. 


\begin{tabular}{|c|c|c|c|c|c|}
\hline \multirow[t]{3}{*}{ Event } & \multicolumn{3}{|c|}{ Engine load closure (in) } & \multirow{3}{*}{$\begin{array}{l}\text { Wlight load } \\
\text { closure (in) }\end{array}$} & \multirow{3}{*}{$\begin{array}{l}\text { Total closure } \\
\text { (in) }\end{array}$} \\
\hline & \multirow{2}{*}{$\begin{array}{l}\text { Axisymmetric } \\
\text { (speed \& thermal) }\end{array}$} & \multicolumn{2}{|c|}{ Asymmetric } & & \\
\hline & & Thrust & I hermal & & \\
\hline Climb (pinch) & -0.031 & -0.006 & -0.005 & -0.004 & -0.046 \\
\hline In-flight restart & -0.039 & -0.002 & +0.001 & -0.002 & -0.042 \\
\hline Thrust reverse & -0.034 & -0.008 & -0.001 & 0.000 & -0.043 \\
\hline Hard turn & -0.033 & -0.007 & -0.001 & -0.005 & -0.046 \\
\hline Airplane stall & -0.031 & -0.008 & +0.002 & -0.007 & -0.044 \\
\hline
\end{tabular}

Table 1: JT9D engine HPT closures due to axisymmetric and asymmetric loads ${ }^{3}$

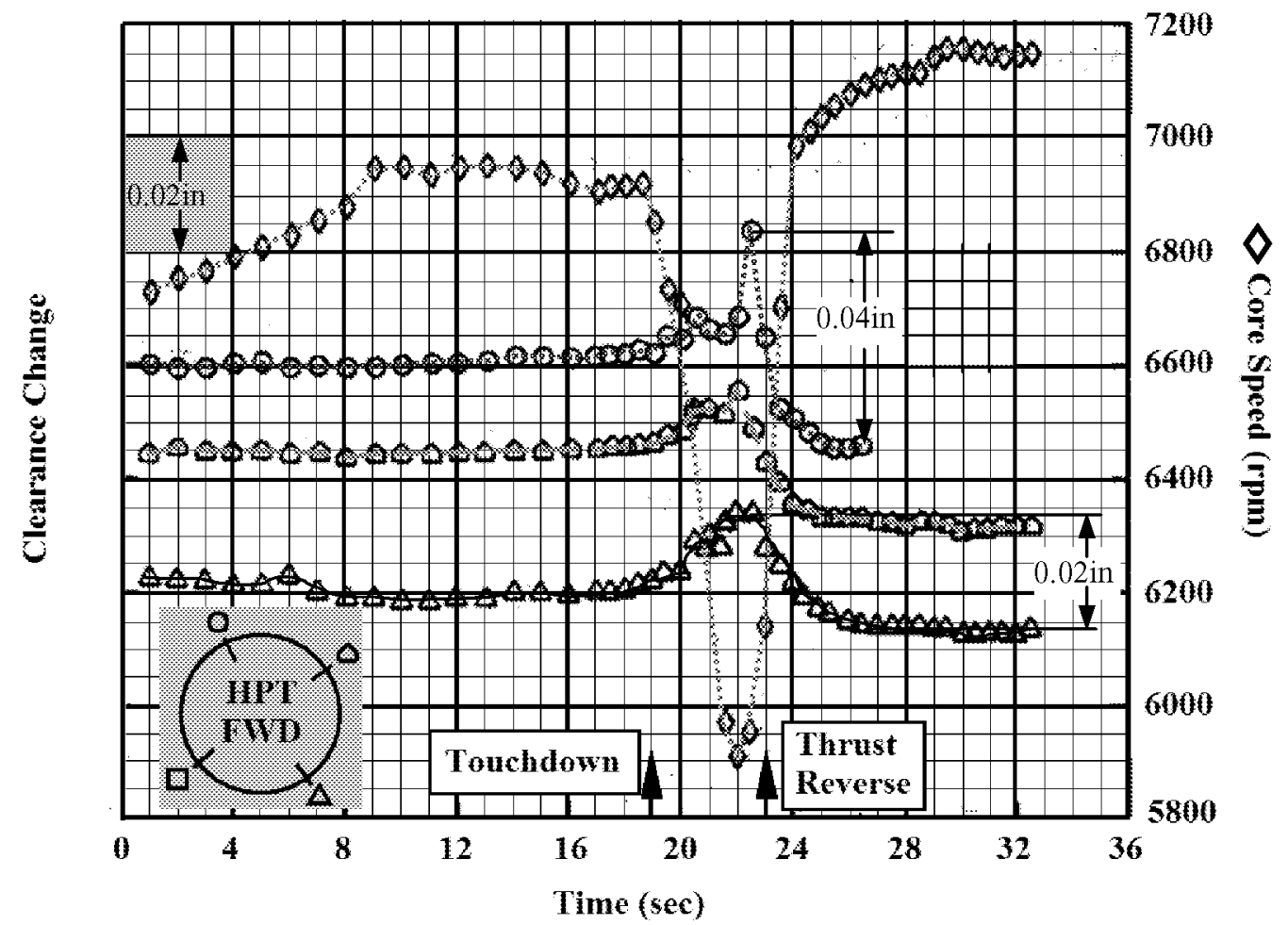

Figure 8: Engine and flight load effects during hard landing and reverse thrust on HPT clearance of JT9D engine ${ }^{3}$ 
loads were experienced during the flight loads testing of the JT9D engine. However, they did estimate that a worst-case gust scenario on the engine would produce an equivalent aerodynamic load less than one-half that experienced during takeoff with no significant contribution to HPT closure.

\section{ENGINE THERMAL STATE}

Engine temperatures play a huge role in determining the operational clearances. One can imagine, referring back to Figure 4 , if the generalized data is for a cold engine start, the takeoff pinch point would be lower for a hot engine at takeoff where the rotor is larger due to its greater thermal mass as compared to the case. Thus, proper cooling time is generally allotted before an aircraft can takeoff with hot engines. Another thermal factor that can affect engine clearances is a phenomenon known as bowed rotor starts. Shortly after engine shutdown, heat begins to build up in the top portion of the engine due to the heat retained in the engine components and lack of venting for this trapped heat. This so-called "chimney effect" can deflect (bow) the low and high-pressure shafts due to the diametral temperature gradient. The maximum deflection generally occurs between 1 to 2 hours after engine shutdown. Thus, if an aircraft's engines are restarted during that period, a bowed rotor start can occur that could create a rub condition along with rotor dynamic issues. Bowed rotor starts have been known to actually lockup the low-pressure shaft due to the LPT blade interference with the LPT shroud.

\section{OTHER MECHANISMS}

Rotor dynamics generally do not play a large role in HPT tip clearance variations. Bearing clearances, locations and shaft designs minimize shaft deflection and operating speeds are kept well below rotor criticals. Manufacturing tolerances of both blade length and casing roundness also contribute little to HPT clearance variations. Dynamics (bearing clearances) and manufacturing tolerances (i.e., shroud roundness, blade length variation) generally add less than 0.010 -in to radial clearance variation.

Although there is a fair amount of axial growth due to thermal loading of the rotor, it does not contribute to HPT tip clearance variation. This effect is much greater in conical shaped sections such as the low-pressure turbine (LPT).

\section{BENEFITS OF REDUCED TIP CLEARANCE}

Gas turbine performance, efficiency, and life are directly influenced by blade tip clearance. Tighter blade tip clearances reduce air leakage over the blade tips.
This increases turbine efficiency and permits the engine to meet performance and thrust goals with less fuel burn and lower rotor inlet temperatures. Because the turbine runs at lower temperatures, while producing the same work, hot section components would have increased cycle life. The increased cycle life of hot section components increases engine service life (TOW) by increasing the time between overhauls.

\section{FUEL SAVINGS}

Engine SFC and EGT are directly related to HPT blade tip clearances. Wiseman et al., indicate that for every 0.001-in increase in HPT tip clearance, SFC increases approximately $0.1 \%$, while EGT increases $1{ }^{\circ} \mathrm{C}$. ${ }^{1}$ Thus, a 0.010 -in HPT tip clearance decrease would roughly produce a $1 \%$ decrease in $\mathrm{SFC}$ and a $10-^{\circ} \mathrm{C}$ decrease in EGT. Military engines generally show slightly greater HPT tip clearance influence on SFC and EGT due to their higher operating speeds and temperatures over large commercial engines. Improvements of this magnitude would produce huge savings in annual fuel and engine maintenance costs. Figure 9 shows the U.S. carrier's fuel usage for the last 25 years along with projected averages for the next 24 years. ${ }^{6}$ Also shown is the projected fuel cost savings based on a $1 \%$ reduction in fuel use, assuming the 2001 average fuel price. The figure shows a significant yearly savings of $\$ 160 \mathrm{M}$ for the year 2002 alone due only to a modest $1 \%$ reduction in SFC. Tip clearance closures of 0.015 -in that are conceivable for advanced ACC systems would further increase the savings. It must also be noted that significant improvements in engine technology have reduced fuel burn by over $50 \%$ since $1976 .^{7}$ The data used in Figure 9 represents the total fuel consumption by major, national and large regional carriers and thus accounts for the increase in fleet size and use of those carriers.

\section{REDUCED EMISSIONS}

Reducing fuel consumption also reduces aero engine total emissions. The Rocky Mountain Institute estimates that Americans alone now fly 764 million trips per year ( 2.85 airline trips per person). The energy used by commercial aircraft has nearly doubled over the last three decades. The increased fuel consumption accounts for $13 \%$ of the total transportation sector emissions of carbon dioxide $\left(\mathrm{CO}_{2}\right){ }^{8}$ Modern aero engine emissions are made up of over $71 \% \mathrm{CO}_{2}$ with about $28 \%$ water $\left(\mathrm{H}_{2} \mathrm{O}\right)$ and $0.3 \%$ nitrogen oxide $\left(\mathrm{NO}_{2}\right)$ along with trace amounts of carbon monoxide $(\mathrm{CO})$, sulfur dioxide $\left(\mathrm{SO}_{2}\right)$, etc. Air transport accounts for $2.5 \%$ (600 million tones) of the world's $\mathrm{CO}_{2}$ Production. ${ }^{7}$ Clearly a reduction in fuel burn will significantly reduce aero engine emissions. 


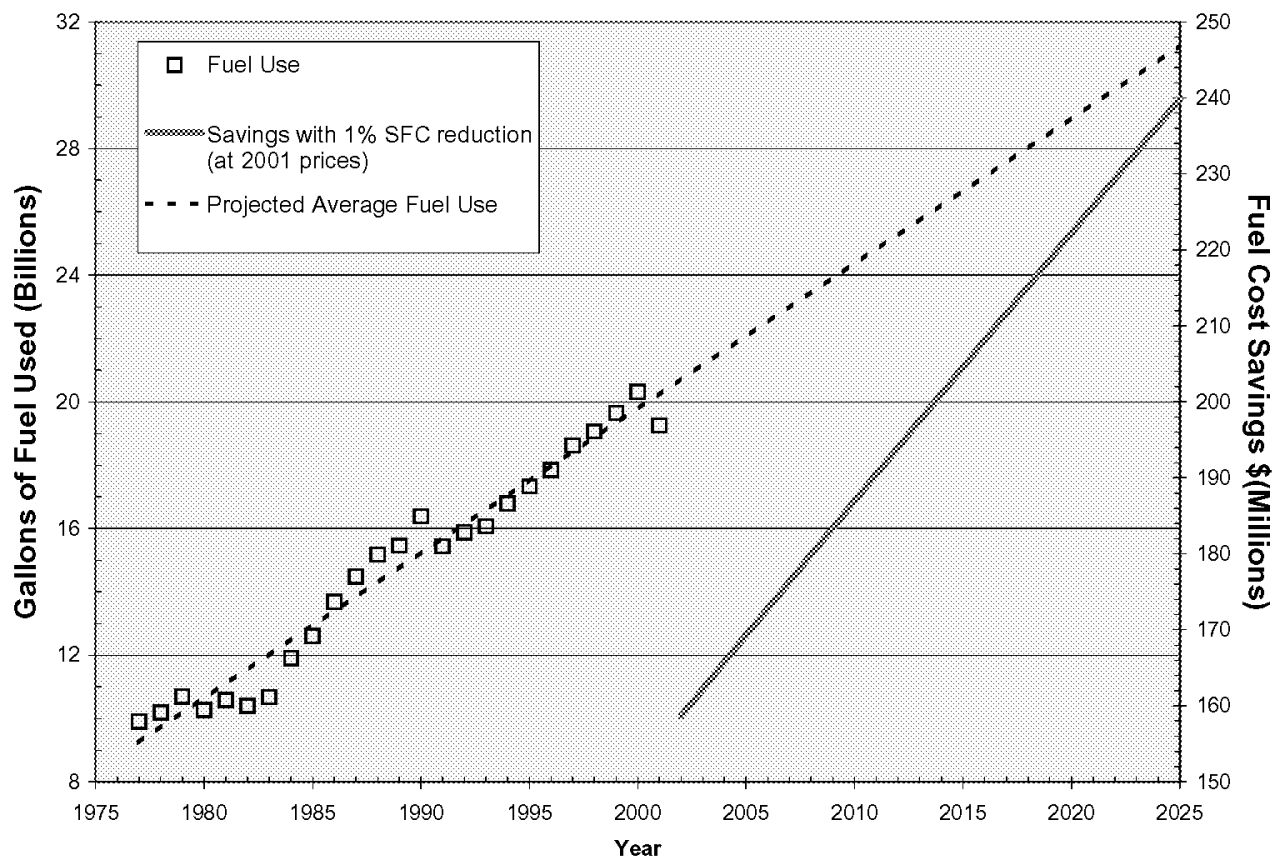

Figure 9: Past and projected fuel use and projected cost savings for a 1\% reduction in SFC (U.S. carriers)

\section{EXTENDED SERVICE LIFE}

Current large commercial engines have life cycles (time between overhauls) that vary significantly (e.g., 3,000 to 10,000 cycles). Their cycle lives are basically determined by how long they retain a positive EGT margin. New engines or newly overhauled engines are shipped with a certain cold build clearance. This clearance increases with time due primarily to rubs early in the engine's life ${ }^{3,9}$. Martin reported a $1 \%$ loss estimate in engine performance due to clearance changes that occurs during the production flight test acceptance profile ${ }^{9}$. As the engine operating clearances increase, the engine must work harder (hotter) to produce the same work and is therefore, less efficient. This increase in operating temperature, particularly takeoff EGT, further promotes the degradation of hot section components due to thermal fatigue. Retaining engine takeoff EGT margin by maintaining tight tip clearances and either eliminating rubs or compensating for them can dramatically increase engine cycle life. This could also lead to huge savings in engine maintenance over a period of years due to the large overhaul costs

\section{HPT BLADE TIP CLEARANCE MANAGEMENT CONCEPTS AND REQUIREMENTS}

Tip clearance management can generally be categorized by two control schemes, active clearance control (ACC) and passive clearance control (PCC). PCC is defined here as any system that sets the desired clearance at one operating point, namely the most severe transient condition (e.g., takeoff, reburst, maneuver, etc.). ACC, on the other hand, is any system that allows independent setting of a desired clearance at more than one operating point. The problem with PCC systems is that the minimum clearance (pinch point) that the system must accommodate leaves an undesired larger clearance during the much longer, steady state portion of the flight (i.e., cruise). PCC systems have been (and still are) used on gas turbine engines. PCC systems include better matching of rotor and stator growth throughout the flight profile, the use of abradables to limit blade tip wear, the use of stiffer materials and machining techniques to limit or create distortion of static components to maintain or improve shroud roundness at extreme conditions, etc. Engine 
manufacturers began using thermal ACC systems in the late 1970's and early 1980's. ${ }^{5,10,11}$ These systems utilized fan air to cool the support flanges of the HPT case, reducing the case and shroud diameters, and hence blade tip clearance, during cruise conditions (see Figure 1). These systems have generally been confined to the HPT and LPT sections. Although some ACC design and production work has been implemented for the HPC section 5 , to the author's knowledge, no engines are flying using ACC in the compressor section.

\section{CLEARANCE CONTROL CONCEPTS}

$\mathrm{PCC}$ and $\mathrm{ACC}$ concepts are not in short supply. There are well over one hundred U.S. patents describing turbine engine blade tip clearance control. Most of the patented concepts can generally be grouped into five major categories, active thermal, active mechanical, passive thermal, active pneumatic, and passive pneumatic.

\section{ACTIVE THERMAL}

Current active thermal designs utilize compressor and fan air to respectively heat (expand) or cool (contract) the shroud seal segment support to vary tip clearance. ${ }^{12}$ These concepts have of course been and remain the staple technology for clearance control in modern gas turbine engines. Figure 1 shows an example of such a system. These systems however are still limited by slow thermal response and therefore do not allow for further closure gains during cruise. Improvements to these systems include the use of more thermally efficient materials and geometries. Ciokajlo ${ }^{13}$ presents a novel approach in which the seal segments are attached to a thermally efficient channel structure that is cooled inside and decoupled from the massive case flange structures enabling a much more responsive ACC system.

\section{ACTIVE MECHANICAL}

Active mechanical designs combine linkages and some actuation (hydraulic, electro-mechanical, magnetic, etc.) to vary the tip clearance. An example of this type of system is a segmented shroud with its segments connected to a unison ring via linkages attached to radially oriented posts (spokes), such that when the ring is rotated in one direction or the other, the segments move radially inward or outward together. ${ }^{14}$ These systems generally require actuation through the case due to the lack of current high temperature actuator capabilities. This requirement subjects these designs to secondary sealing issues, tolerance stack ups due to the number of linkages used, as well as increased weight and mechanical complexity. While these issues may all be overcome, the biggest issue is positioning control.
Currently there are no clearance measuring sensors that can reliably survive the operating temperatures and vibration levels at the tip seal location for extended periods of time (over 50 hours). This problem may be overcome with improved high temperature sensing electronics that are currently being developed.

\section{PASSIVE THERMAL}

Passive thermal systems rely on material properties and engine operating temperatures to match rotor and stator growths. These approaches are generally used on today's smaller engines. Carpenter et al., ${ }^{15}$ describe a system which combines stator materials with different coefficients of thermal expansion to allow faster growth of the shroud at lower temperatures to better match the centrifugal growth of the rotor (during takeoff while the case is still heating) and slower growths at higher temperatures (during climb when the rotor is only growing due to thermal effects). To the authors' knowledge, this type of PCC is not currently being used on any engines. While passive thermal systems may be accurate and reliable, they will only provide optimum clearance for the minimum clearance condition (takeoff, maneuver, etc.) and do not capitalize on the longer stabilized cruise condition of the flight profile.

\section{ACTIVE PNEUMATIC}

Active pneumatic concepts utilize internally generated engine pressure or externally generated pressure and valving to load deflectable, sealed shroud segments directly or through some bellows arrangement to radially vary tip clearance. ${ }^{16}$ These systems can be subject to high cycle fatigue (HCF) and are very sensitive to pressure balancing. They can require a great deal of system pressure or auxiliary pressure sources, which would detract from engine efficiency.

\section{PASSIVE PNEUMATIC}

Passive pneumatic systems are driven by engine generated gas pressures or hydrodynamic effects. Concepts such as floating shroud segments ${ }^{17}$ and blade tip cooling air discharge ${ }^{18}$ fall into this category. Any systems relying on hydrodynamic generated force are subject to very limited surface area (blade tips), extremely high positioning and alignment tolerance requirements, friction and secondary seal hang-up that make these concepts very unattractive. Pneumatic systems that rely on flexible walls or bellows arrangements are subject to HCF from the flexing and thinness of materials that their operation requires, not too mention high vibration, thermal and pressure loading stresses that the components must endure in the HPT environment. 


\section{REGENERATION}

The previously mentioned clearance control concepts all dealt with passive or active variations to blade tip clearance with the intent of maintaining some clearance at all operating conditions as to avoid blade rubs. Another clearance control category exists which is recognized separately from the "rub-avoidance" type approaches. This is the category of tip seal restoration or regeneration. Concepts in this category utilize both passive and active control to restore deteriorated tip seals due to rubs and erosion. Examples of these concepts include mechanically adjusted linkages that allow for ground maintenance of tip seal restoration and seal material systems that undergo permanent volume changes.

Mechanical restoration concepts are subject to the same tolerance issues as the active mechanical designs. Secondary sealing may not be as big an issue because these systems don't provide clearance adjustment during flight operation. There is still a weight issue with the additional hardware, although the actuation driver is no longer part of the system. The major issue with this concept is the accessibility of the adjusting mechanism(s) for routine ground maintenance.

Regenerative seal concepts are envisioned to utilize specially engineered material systems that undergo permanent volume changes (growth) due to thermal, chemical, electrical interactions (e.g., oxidation ${ }^{19}$ ). These systems have the potential for operating in the HPT and utilizing the environment (temperature, air, etc.) for passive control. These systems also have the potential for active control (chemical reactions can be accelerated and decelerated due to electric potential, ${ }^{20}$ additives, temperature, etc.). Regenerative systems are subject to uniformity issues (i.e., how uniformly does the material grow around the circumference), directional issues (i.e., the system should grow radially not axially), as well as strength, and growth limit issues. Another concern for any restoration system is controlling growth to prevent excessive blade wear.

\section{ACC REQUIREMENTS}

For any of the previously mentioned clearance management concepts to be viable in a commercial or military gas turbine engine many technical and economical requirements must be met. Technical requirements are defined here as operational conditions (temperature, pressure, vibration, etc.) and operational functionality (radial clearance change, response rate, cycle life, positional accuracy, concentricity, ability to maintain shroud roundness, output force, etc.). Economic requirements include size (space claim), weight, manufacturability, maintenance, reliability, and material cost.

\section{ACTUATION RANGE, RESPONSE RATE AND ACCURACY}

The largest HPT tip clearance variations, as shown previously, are due to centrifugal growth of the rotor during takeoff and reburst conditions. Maximum tip clearance changes due to axisymmetric and asymmetric loads on the rotor and stator components are on the order of 0.050 -in. The FAA requires that gas turbine engines have the ability to reach $95 \%$ rated takeoff power from flight idle (or from 15\% rated takeoff power) in 5.0 seconds. ${ }^{21}$ In general, this requirement sets a limiting case of maximum displacement and minimum response time for actuation systems to be used as ACC. Assuming a maximum clearance change of $0.050-\mathrm{in}$, this would require actuation systems that can provide radial clearance change on the order of $0.010-\mathrm{in} / \mathrm{s}$. These response rates would obviously exclude faster dynamic clearance changes (i.e., once per revolution events).

Positional and dimensional accuracy is extremely important in a gas turbine engine. Sealing and rotor dynamic issues depend on high manufacturing and assembly tolerances. Any mechanical ACC system that is attempting to control tip clearances to within 0.010 -in or better must be precisely designed. Linkage and device tolerances, large temperature variations, high vibrations, and significant loads present design challenges in reaching positional accuracy goals. Current thermal cooling ACC systems in general do not close cruise clearances below 0.015 to 0.020 -in. This is due to the margin of safety required by the slow system response in the event of throttle transients (e.g., step change in altitude) or maneuvers at cruise. Thus, significant potential exists for reduced HPT clearances using faster response ACC systems.

\section{ACTUATOR FORCE}

The backside of the HPT shroud (blade outer-air-seal) is generally cooled with compressor discharge air $\left(\mathrm{T}_{3}\right.$ air: 1200 to $1300^{\circ} \mathrm{F}$ ). This cooling is necessary for the shroud segments to survive the $2500^{\circ} \mathrm{F}$ and higher rotor inlet gas temperatures. The cooling air is also used to purge the leading and trailing edges of the shroud segments, providing a positive back-flow margin from the hot rotor inlet flow. This cooling flow is shown in Figure 10 for the first stage shroud of a two-stage HPT. The pressures surrounding the shroud segment can be expressed as a function of the compressor discharge pressure $\left(\mathrm{P}_{3}\right)$. Pressure inside the HPT shroud varies axially due to the work extracted by the turbine blades. 


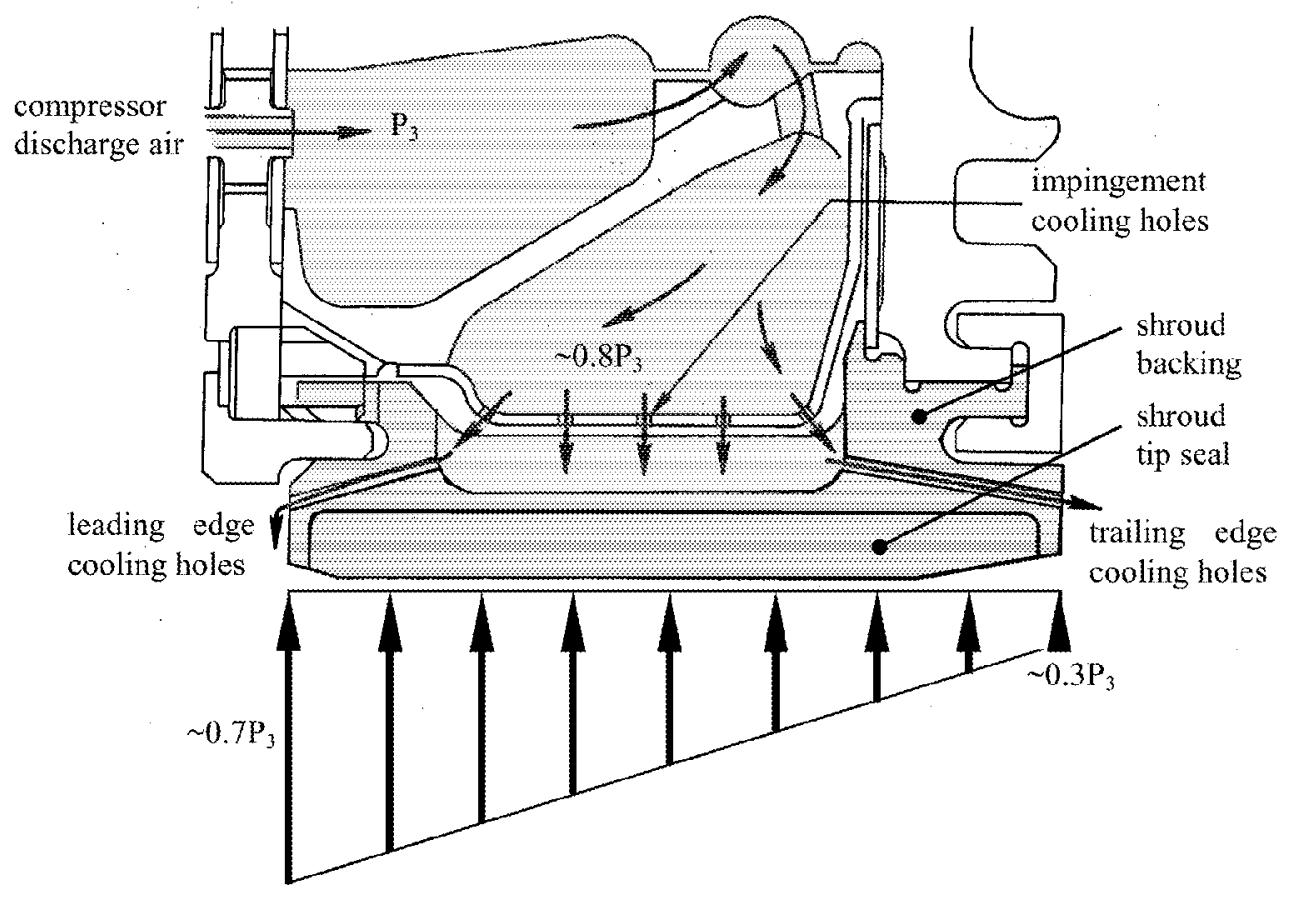

Figure 10: Axial pressure distribution across HPT blade tip seal cross section

For large commercial engines, the pressure of the cooling air behind the shroud is about 60 to $80 \%$ of the compressor discharge pressure (CDP). Pressure in the tip clearance region varies axially from the leading to the trailing edge of the shroud about 70 to $30 \%$ of the CDP, respectively. To maintain a positive backflow margin from the rotor inlet air, the cooling pressure on the backside of the shroud must always be higher than the rotor inlet side. The radial pressure difference across the shroud creates a load inward to the shaft centerline. An ACC system must be able to overcome this load as well as the resultant moment created by the non-uniform axial pressure distribution. Assume the average pressure drop across the HPT shroud of a large 2 -stage turbo fan engine is about 120 psi. For a 30 -in shroud inner diameter, 2-in wide, a 120-psi average pressure drop across the shroud diameter would produce a force of about $240 \mathrm{lbf} / \mathrm{in}$ on the shroud diameter. If the shroud were made of 16 segments, approximately 6-in long, this pressure difference would translate to $1,440 \mathrm{lbf}$ per segment. Positioning the shroud segments in the presence of these pressure loads to the required accuracy (e.g., $\leq 0.005$-in) poses some unique design challenges. Therefore care must be used in choosing the proper actuation mechanism in an ACC design.

\section{THERMAL ENVIRONMENT}

HPT rotor inlet gas temperatures range from 2000 to $3000^{\circ} \mathrm{F}$. The use of advanced high temperature alloys, ceramics, and thermal barrier coatings have allowed current turbines to run at these higher temperatures. HPT shrouds must be cooled, as previously mentioned. The backsides of the shroud are cooled with CDP air $\left(T_{3}\right)$, which generally ranges in temperature from 1200 to $1300^{\circ} \mathrm{F}$. These temperatures severely limit the material choices that can be used in this environment. The casing that surrounds the shroud can have metal temperatures over $700^{\circ} \mathrm{F}$ during takeoff conditions for large engines. Air temperatures outside the casing may be 100 to $300^{\circ} \mathrm{F}$ and can obviously be used to cool actuators mounted outside the HPT casing. However, great care must be taken to ensure positioning tolerances due to extended linkages and secondary sealing issues do not negate the benefits of cooler temperatures outside the casing.

\section{ACC ACTUATORS}

There have been major developments in the areas of advanced actuators and smart materials in the last twenty years. Piezoelectric actuators and sensors have found many applications from miniature motors for optical positioning to active twist control for helicopter 
rotor blades. Shape memory alloys have undergone major improvements in design capabilities and cycle life. However these systems and materials do not currently possess the temperature capability to be considered for direct use inside the HPT without major cooling schemes. Actuation of high temperature metals via thermal expansion/contraction provides a very reliable, accurate, and predictable system albeit fairly slow response. The response can of course be improved with more thermally efficient materials and geometries, however care must be taken to ensure that structural integrity is not compromised. Hydraulic actuation has also been reliably used in gas turbine engines. Fuel is currently used for valve actuation (fuel, start bleed, and cooling) and actuation of fan and compressor inlet guide vanes. ${ }^{22}$ Military engines with thrust vectoring and area control exhaust nozzles also utilize highpressure fuel (3500 psi) for actuation. Obviously, great care must be taken when designing fuel-powered hydraulic systems to prevent both ignition and fuel deposits due to high ambient temperatures.

\section{ACC CONTROL}

In general, three classifications of control schemes have been considered for tip clearance management, namely on/off, model-based, and feedback control. On/off control provides two-position actuation that can be optimized at only one operating point. This concept is widely used in current ACC systems because of the limited clearance variation during cruise. Kawecki reported that for military transport aircraft, nearly $89 \%$ of the fuel and $93 \%$ of the time is spent at cruise in comparison to a fighter aircraft where cruise was responsible for $69 \%$ of the fuel burned and $75 \%$ of the mission time. ${ }^{2}$ Thus, nearly all of the benefit available during a flight can be achieved with a single closedown. However, this does not account for detrimental clearance changes during operating transients. Modelbased control utilizes engine-operating information (i.e., speed, temperature, and pressure measurements) to estimate clearance as a function of operating conditions. This control scheme allows the clearance to be set at more than one operating point. Model-based systems require the clearances to be held at some intermediate position depending on the operating point. Feedback control assumes that the clearance is continuously measured throughout the flight. This control scheme also requires high positional accuracy with little hysteresis.

\section{FAILSAFE OPERATION}

Any system that can affect the operation of the engine must be failsafe. For ACC systems, if adequate clearance is not maintained during any portion of engine operation, significant damage to shrouds and rotor components may result. This may not only counter-act the effect of the ACC system (improved $\mathrm{SFC}$, increased engine life, etc.) but could also create an in-flight engine failure if closure is severe enough. Therefore any system must guarantee that such catastrophic events could not occur. Sensor and actuator redundancy, biased clearance opening, and ACC system health monitoring are techniques that can be used to achieve failsafe operation.

\section{TIP CLEARANCE SENSORS}

Researchers and engine manufacturers have been using blade tip sensors for tip clearance and blade vibration measurement for over 30 years. Many different technologies have been utilized for this purpose including x-ray, capacitive, inductive, optical, eddycurrent, microwave, and acoustic. Typical blade passage sensors provide the ability to measure blade tip clearance and time of arrival. Flotow, et. al, provide a detailed review of blade sensing technology as well as how the blade passage signal can be interpreted for rotor and blade health monitoring. ${ }^{23}$

Tip clearance measurement may be required for any ACC systems that are to improve upon and replace the current technology. The sensors should have accuracy on the order of $0.001-\mathrm{in}$. The sensors must have accuracies well below the inherent engine and ACC system tolerance stack ups so as not to detract from the ACC system. Sensor response requirements will vary depending on the desired measurement (clearance measurement, blade health, etc.). For clearance measurement, sensor response should be on the order of $50 \mathrm{kHz}$. This response will allow multiple clearance measurements per blade for large engines. Sensors and communication hardware will have to be durable with long service life (e.g., over 20,000 flight hours). This requires high temperature capability (or adequate cooling schemes), high vibration and impact tolerance. Due to the engine environment, sensors should be tolerant to moisture, dirt or combustion products in the gas stream. Sensors must be easily maintained with the ability to be calibrated or replaced at regularly scheduled intervals that are already determined by other unrelated engine components.

\section{FUTURE DIRECTIONS}

The authors are currently investigating two approaches for tip clearance management. The first approach is rub-avoidance, where an ACC system would be utilized to maintain adequate blade tip clearance at all operating points using feedback and or model-based control. The second approach, regeneration, would employ either a passive or active system that would restore worn tip 


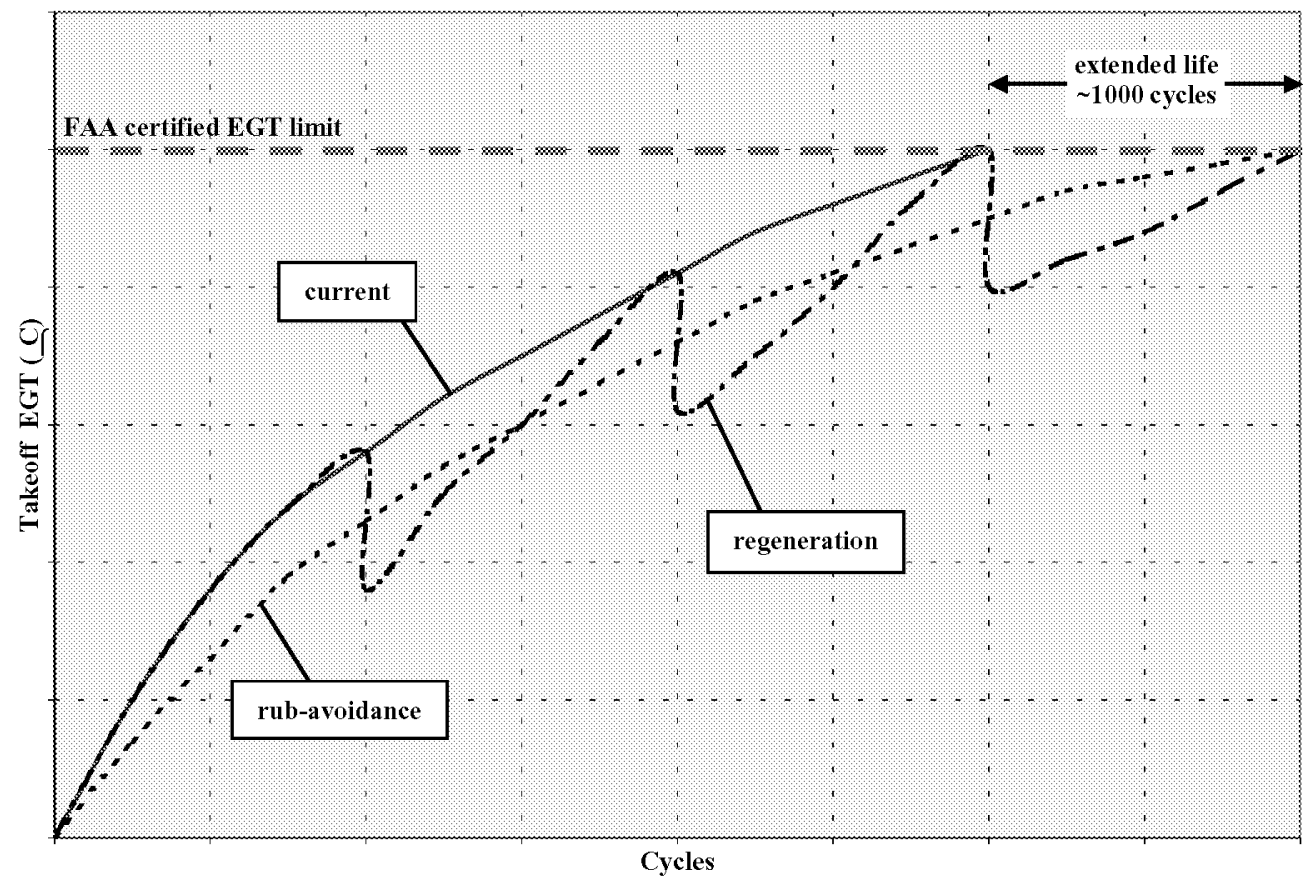

Figure 11: Effect of rub-avoidance and regeneration $\mathrm{ACC}$ schemes on takeoff EGT

seals due to both blade rubs and erosion. Figure 11 graphically depicts how both the rub-avoidance and regeneration systems would extend engine service life by slowing the rate of takeoff EGT growth as compared to current $\mathrm{ACC}$ systems. The rub-avoidance systems under consideration would prevent tip seal wear due to blade rubs and could conceivably adjust tip clearances to compensate for erosion throughout engine service life. Although pinch point clearances may run slightly larger than current ACC systems, which generally run line-to-line, due to system tolerances (manufacturing, assembly, operation, etc.), the rate of EGT rise would decrease because the operating clearance outside the pinch points would be tighter than current $\mathrm{ACC}$ systems. Regeneration schemes could be applied to both current and future ACC systems. Figure 11 depicts their benefits as applied to current ACC technology, where periodically (e.g., at 1000 cycle intervals) the system would be activated during routine ground servicing, restoring worn tip clearances and hence, lowering takeoff EGT. The authors believe that either of these approaches, if properly developed, would extend engine service life by 1000 cycles or more. It is worth noting that Figure 11 does show EGT eventually reaching the FAA certified limit for current ACC as well as the rub-avoidance and regeneration approaches. As previously mentioned, other factors (blade wear, HPC blade fouling, LPT tip seal wear, etc.) contribute to engine performance losses and hence EGT increase.

\section{CONCLUSIONS}

HPT performance degradation begins early in a new or refurbished engine, usually in the first few flights of operation. The initial degradation comes from blade tip seal wear due to combinations of axisymmetric and asymmetric clearance closure mechanisms that are not encountered during ground test stand operation. This initial wear can account for losses in HTP performance of $1 \%$ or more. The increased tip clearance accelerates effects of low cycle fatigue and erosion due to increased temperatures in the HPT and degrades EGT margin and engine life. In general, for large gas turbine engines, tip clearance reductions on the order of 0.010 in can produce decreases in SFC of $1 \%$ and EGT of 10 ${ }^{\circ} \mathrm{C}$. Improved tip clearances of this magnitude can produce fuel and maintenance savings over hundreds of millions of dollars per year. Reduced fuel burn will also reduce aircraft emissions, which currently account for $13 \%$ of the total U.S. transportation sector emissions of $\mathrm{CO}_{2}$. Presently, these savings are unrealized due to the slow response of current ACC systems and the lack of direct tip clearance measurement. Improved ACC systems will seek to further reduce cruise clearances (nominally 0.015-0.020-in) while eliminating blade rubs to make significant impact on SFC and takeoff EGT margin. 


\section{NOMENCLATURE}

$\begin{array}{ll}\text { ACC } & \text { Active clearance control } \\ \text { CDP } & \text { Compressor discharge pressure } \\ \text { EGT } & \text { Exhaust gas temperature } \\ \text { FAA } & \text { Federal Aviation Administration } \\ \text { ft/s } & \text { Feet per second } \\ \text { HCF } & \text { High cycle fatigue } \\ \text { HPC } & \text { High pressure compressor } \\ \text { HPT } & \text { High pressure turbine } \\ \text { in } & \text { Inches } \\ \text { krpm } & \text { (Revolution per minute)x1000 } \\ \text { lbf } & \text { Pound force } \\ \text { lbf/in } & \text { Pound force per inch } \\ \text { LCC } & \text { Life cycle cost } \\ \text { LPT } & \text { Low pressure turbine } \\ { }^{\circ} \mathrm{C} & \text { Degrees Celsius } \\ { }^{\circ} \mathrm{F} & \text { Degrees Fahrenheit } \\ \mathrm{P}_{3} & \text { Air pressure exiting high pressure compressor } \\ \text { PCC } & \text { Passive clearance control } \\ \text { psi } & \text { Pound-force per square inch } \\ \text { rpm } & \text { Revolution per minute } \\ \text { SFC } & \text { Specific fuel consumption } \\ \text { T3 } & \text { Air temperature exiting high-pressure } \\ & \text { compressor } \\ \text { TOW } & \text { Time-on-wing }\end{array}$

\section{REFERENCES}

${ }^{1}$ Wiseman, M.W., Guo, T. "An Investigation of Life Extending Control Techniques for Gas Turbine Engines", Proceedings of the American Control Conference, Arlington, VA, June 25-27, 2001.

${ }^{2}$ Kawecki, E.J., "Thermal Response Turbine Shroud Study," Air Force Aero Propulsion Laboratory Technical Report AFAPL-TR-79-2087, 1979.

3 Olsson, W.J., Martin, R.L., "B747/JT9D Flight Loads and Their Effect on Engine Running Clearances and Performance Deterioration; Nacelle Aerodynamic and Inertial Loads (NAIL)/JT9D Jet Engine Diagnostics Programs," NASA CR-165573, 1982.

4 Howard, W.D., Fasching, W.A., "CF6 Jet Engine Diagnostics Program; High Pressure Turbine Roundness/Clearance Investigation," NASA CR$165581,1982$.

5 Halila, E.E., Lenahan, D.T., Thomas, T.T., "Energy Efficient Engine, High Pressure Turbine Test Hardware Detailed Design Report," NASA CR-167955, 1982.

${ }^{6}$ Bureau of Transportation Statistics, 4007 th Street, SW, Room 3103, Washington, DC 20590

${ }^{7}$ European Regions Airline Association (ERA), "ERA Fast Facts," September 2001.
${ }^{8}$ Rocky Mountain Institute (RMI), "Climate, Air Travel Emissions," 2002.

9 Martin, R.L., "Nacelle Aerodynamic and Inertial Loads (NAIL) Project, Test Report," NASA CR165760,1981

${ }^{10}$ Gaffin, W.O., "JT9D-70/59 Improved High Pressure Turbine Active Clearance Control System," NASA CR$159661,1979$.

11 Fasching, W.A., "CF6 Jet Engine Performance Improvement Summary Report," NASA CR-165612, 1982.

12 Kolthoff, P., "Device for Controlling Clearance Between Rotor and Shroud of a Turbine," U.S. Patent $3,039,737,1962$.

13 Ciokajlo, J.J., "Blade Tip Clearance Control Apparatus Using Shroud Segment Annular Support Ring Thermal Expansion," U.S. Patent 5,116,199, 1992.

14 Tseng, W., Hauser, A.A., "Blade Tip Clearance Control Apparatus with Shroud Segment Position Adjustment by Unison Ring Movement," U.S. Patent $5,035,573,1991$.

${ }^{15}$ Carpenter, K.D., Wiedemer, J.D., Smith, P.A., "Rotor Blade Outer Tip Seal Apparatus," U.S. Patent $5,639,210,1997$.

16 Catlow, R., "Blade Tip Clearance Control Apparatus," U.S. Patent 5,211,534, 1993.

${ }^{17}$ Wardle, R.L., "Floating Blade Shrouds," U.S. Patent 2,927,724, 1960.

${ }^{18}$ Huber, F.W., Dietrich, D.J., "Clearance Control for the Turbine of a Gas Turbine Engine," U.S. Patent $5,667,359,1997$

${ }^{19}$ Cawley, J.D., "Oxidizing Seal for Turbine Tip Gas Path,” U.S. Patent 4,540,336, 1985.

20 Jorgensen, P.J., "Effect of an Electric Field on Silicon Oxidation," The Journal of Chemical Physics, vol. 37, no. 4, 1962.

${ }^{21}$ Electronic Code of Federal Regulations, Title 14, Aeronautics and Space, Chapter I, Federal Aviation Administration, Department of Transportation, Part 33, Airworthiness Standards: Aircraft Engines, 33.73 Power or Thrust Response, Amdt. 33-1, 36 FR 5493, Mar. 24, 1971

${ }^{22}$ Eder, M., "Engine Fuel System Design Issues," Aviation Fuels with Improved Fire Safety: A Proceedings, pp. 61-64, National Academy Press, Washington, D.C. 1997.

23 Flotow, A., Mercadal, M., Tappert, P., "Health Monitoring and Prognostics of Blades and Disks with Blade Tip Sensors," Aerospace Conference Proceedings, IEEE, Vol. 6, pp. 433-440, 2000. 



\section{\begin{tabular}{l|l|l} 
1. AGENCY USE ONLY (Leave blank) & 2. REPORT DATE & 3. REPORT TYPE AND DATES COVERED
\end{tabular}}

\begin{tabular}{|l|l|l}
\hline & September 2002 & Technical Memorandum \\
\hline
\end{tabular}

\begin{tabular}{l|l} 
4. TITLE AND SUBTITLE & 5. FUNDING NUMBERS
\end{tabular}

Turbine Engine Clearance Control Systems: Current Practices and

Future Directions

6. AUTHOR(S)

WU-708-87-13-00

Scott B. Lattime and Bruce M. Steinetz

7. PERFORMING ORGANIZATION NAME(S) AND ADDRESS(ES)

National Aeronautics and Space Administration

John H. Glenn Research Center at Lewis Field

Cleveland, Ohio 44135-3191

8. PERFORMING ORGANIZATION

REPORT NUMBER

E-13489

9. SPONSORING/MONITORING AGENCY NAME(S) AND ADDRESS(ES)

10. SPONSORING/MONITORING

AGENCY REPORT NUMBER

National Aeronautics and Space Administration

Washington, DC 20546-0001

NASA TM-2002-211794

AIAA-2002-3790

\section{SUPPLEMENTARY NOTES}

Prepared for the 38th Joint Propulsion Conference and Exhibit cosponsored by AIAA, ASME, SAE, and ASEE, Indianapolis, Indiana, July 7-10, 2002. Scott B. Lattime, Ohio Aerospace Institute, Brook Park, Ohio 44142, and Bruce M. Steinetz, NASA Glenn Research Center. Responsible person, Scott B. Lattime, organization code 5950, 216-433-5953.

12a. DISTRIBUTION/AVAILABILITY STATEMENT 12b. DISTRIBUTION CODE

Unclassified - Unlimited

Subject Category: 37

Distribution: Nonstandard

Available electronically at bttp:/ghtr.grenasi.gov

This publication is available from the NASA Center for AeroSpace Information, 301-621-0390.

13. ABSTRACT (Maximum 200 words)

Improved blade tip sealing in the high pressure compressor (HPC) and high pressure turbine (HPT) can provide dramatic reductions in specific fuel consumption (SFC), time-on-wing, compressor stall margin, and engine efficiency as well as increased payload and mission range capabilities. Maintenance costs to overhaul large commercial gas turbine engines can easily exceed $\$ 1 \mathrm{M}$. Engine removal from service is primarily due to spent exhaust gas temperature (EGT) margin caused mainly by the deterioration of HPT components. Increased blade tip clearance is a major factor in hot section component degradation. As engine designs continue to push the performance envelope with fewer parts and the market drives manufacturers to increase service life, the need for advanced sealing continues to grow. A review of aero gas turbine engine HPT performance degradation and the mechanisms that promote these losses are discussed. Benefits to the HPT due to improved clearance management are identified. Past and present sealing technologies are presented along with specifications for next generation engine clearance control systems.

14. SUBJECT TERMS

15. NUMBER OF PAGES

Blade tip clearance; Active clearance control; Engine efficiency; Turbine seal; Specific fuel consumption; Exhaust gas temperature; Time on wing; High pressure turbine

\begin{tabular}{|c|c|c|}
\hline $\begin{array}{c}\text { 17. SECURITY CLASSIFICATION } \\
\text { OF REPORT } \\
\text { Unclassified }\end{array}$ & $\begin{array}{c}\text { 18. SECURITY CLASSIFICATION } \\
\text { OF THIS PAGE } \\
\text { Unclassified }\end{array}$ & $\begin{array}{c}\text { 19. SECURITY CLASSIFICATION } \\
\text { OF ABSTRACT } \\
\text { Unclassified }\end{array}$ \\
\hline
\end{tabular}

NSN 7540-01-280-5500 